\title{
PSYCHOLOGICAL EMPOWERMENT AND JOB SATISFACTION OF ENGINEERS IN A PETROCHEMICAL INDUSTRY
}

\author{
J H Buitendach and R B T Hlalele
}

School of Behavioural Sciences, North-West University, Vaal Triangle Campus

\begin{abstract}
The objective of this study was to determine the relationship between psychological empowerment and job satisfaction of engineers in a chemical industry. A cross-sectional design was used. Stratified random samples of engineers $(N=91)$ were taken. The Measuring Empowerment Questionnaire and the Minnesota Job Satisfaction Questionnaire were used as measuring instruments. Pearsonmoment correlations indicated a correlation of large effect between psychological empowerment and job satisfaction. Overall empowerment was found to be positively related to all satisfaction subscales. Positive correlations of large effect were obtained between job satisfaction and meaning, impact, and self-determination. A positive correlation of medium effect was obtained between job satisfaction and competence. Multiple regression analysis indicated that 70.5 per cent of the variance of job satisfaction was explained by subdimensions of psychological empowerment, although impact was not found to hold a significant amount of predictive value with regard to job satisfaction.
\end{abstract}

JEL A14, D31, J21, L72

1

\section{Problem statement}

Organisations in South Africa, just as in the rest of the world, are continuously under pressure to undergo dramatic changes. Maitland (2002) attributes this to technological and market revolutions that combined and coalesced to produce seismic shifts in the nature of work in the social and technical organisation of productive economic activity. In response to this global challenge, many big organisations delayered, devolved decision-making, promoted multi-skilling, encouraged teamwork and introduced a range of initiatives all designed to empower employees.

Shackleton (1995) defines empowerment as a philosophy of giving more responsibility and decision-making authority to more junior people in the organisation and compares it to delegation. The Oxford English Dictionary defines empowerment as "to invest legally or formally with power or authority" and secondly "to impart or bestow to an end or for a purpose, to enable, permit, and to make powerful".

Eccles (1993) describes empowerment as a process of encouraging employees, including management, to utilise their skills and experience by giving them the power to use more judgement and discretion in their work.

Lashley (1999) defines empowerment as a process that provides autonomy to employees through the sharing of appropriate information and the provision of control circumstances that effect job performance of the organisation, with employees being rewarded for contributions made and with the power to make influential decisions being vested in employees. Peters (1997) shares the view of the above authors that employees must receive the information they need to make decisions in order to empower them. Cloete, Crous, and Schepers (2002) support this by perceiving the concept of empowerment as being related to participation and involvement in decision-making. 
Siegall and Gardner (2000) argue that for empowerment to be effective, employees must first perceive themselves as empowered. For this reason, Block (1987) maintains that the notion of empowerment being taught in a programme, and the prevailing attitude that someone in a position of authority can empower an employee, are simply incongruent with the conscious decision of an individual to act in an empowered way.

Menon (2001) has found that, based on the underlying thrust and emphasis of the various streams of research, there are three broad categories of empowerment, namely the structural, leadership and motivational approach.

The situational approach defines empowerment as being influenced by external factors. Conger and Kanungo (1988) mention that managers can empower employees when they share information, provide structure, develop a team-based approach, offer relevant training opportunities, and reward employees for the initiatives they have taken. The leadership approach is based on the energising aspect of empowerment Menon (2001) indicates that leaders inspire subordinates to participate in the process of transforming the organisation. In this approach factors such as personal mastery, self-efficacy and self-esteem are important (Appelbaum \& Honeggar, 1998). Conger and Kanungo (1988) take an individual motivational approach to empowerment and define it as a process of enhancing feelings of self-efficacy of employees through the identification of conditions that foster powerlessness. The term empowerment refers in this context to psychological aspects, which consist of a set of conditions necessary for intrinsic motivation. Over the past decade, many researchers and practitioners have embraced psychological empowerment as a means of increasing decision-making at lower organisational levels while at the same time enriching the work lives of employees (Liden \& Tewksbury, 1995). Menon (2001) defines psychological empowerment as a cognitive state characterised by a sense of perceived control, competence, and goal internalisation. Psychological empowerment thus reflects an individual's active orientation to his or her work role, and a working environment shapes his or her cognitions (Spreitzer, 1995). The employee must experience the psychological dimension of empowerment in order for the organisation to achieve its desired results and to install a sense of empowerment in its workers. The psychological point of view stresses the fact that empowerment is not a personality disposition, but rather that it is a dynamic construct that reflects individual beliefs about personenvironment relationship (Mishra \& Spreitzer, 1998).

The focus of the current research is on the motivational approach, which emphasises the individual motivational aspects of the empowerment process (Kizilos, 1990). Spreitzer (1995) points out that psychological empowerment differs from structural empowerment in that it focuses on intrinsic motivation (psychological empowerment) rather than on the management practices used to increase individuals' level of power. Menon (2001) explains that from the structural approach, empowerment denotes the internal processes of the individual being empowered.

When sanctions against apartheid were lifted, the organisation in this research was no longer protected from international competitors and this organisation decided to enter the global market. To compete in the international arena the organisation had to cut down on fixed costs.

The objective of this study was to determine the relationship between psychological empowerment and job satisfaction of engineers in a chemical industry. Secondly, to determine whether psychological empowerment can be used to predict job satisfaction. The reason why engineers were targeted in this research, is that they are a very specialised field. Although the engineers work under supervision after completion of their studies, it is expected from them to be able to make decisions. If they experience psychological empowerment, they will most probably be able to make decisions.

\subsection{Empowerment and job satisfaction}

Recently, organisational researchers have started to focus on empowering management 
practices such as delegation of decision-making and increasing access to information and resources (Spreitzer, 1995). Empowerment in this context is viewed from a situational perspective. Lately organisational researchers have taken an interest in psychological empowerment in the workplace (Conger \& Kanungo, 1988; Spreitzer, 1995, 1996; Thomas \& Velthouse, 1990). Psychological empowerment differs from structural empowerment in that it focuses on employees' fundamental beliefs and experiences about their roles in the organisation, rather than on management practices addressing what an organisation can and should do to humanise work and release hidden resources (Corsun \& Enz, 1999).

Kraimer, Seibert and Liden (1999) point out that psychological empowerment reflects individuals' psychological reactions to their work environments. Beach (1996) argues that it involves the creation of an intrinsic desire to take charge of one's life, rather than a mere transmission of organisational power to individuals through a mechanical process of some sort. The psychological frame of mind of the individual employee becomes relevant to the success or failure of the empowerment initiatives.

Conger and Kanungo (1988) define empowerment as the motivational concept of self-efficacy. They describe it as a process of enhancing feelings of self-efficacy among organisational members through the identification of conditions that foster powerlessness and through the removal of both formal organisational practices and informal techniques of providing self-efficacy information. Thomas and Velthouse (1990) further argue that empowerment can be defined from a psychological perspective, explaining that empowerment is intrinsic motivation, manifested in the four cognitions of meaning, competence, self-determination and impact. These four cognitions reflect an individual's active orientation to shape his/her work role and context.

Meaning is the value of a work goal or purpose, judged in relation to an individual's own ideal standards (Thomas \& Velthouse, 1990). According to Brief and Nord (1990) and
Hackman and Oldham (1980), meaning involves a match between requirements of a work role and beliefs, values and behaviours. It involves the individual's intrinsic caring about a given task. According to Appelbaum and Honeggar (1998: 2) "the feeling of meaningfulness is the feeling that you are on a path that is worth your time and energy; that you are on a valuable mission; that your purpose matters in the larger scheme of things". Spreitzer, Kizilos and Nason (1997: 46) postulate that "meaning serves as the engine of empowerment, if employees' hearts are not in their work, if their work activity conflicts with their value system, then they will not feel empowered". Thomas and Velthouse (1990) argue that the notion of personal value fulfilment and job satisfaction results from the perception that one's work fulfils or allows the fulfilment of one's desired work values. Such value fulfilment is consistent with the meaningful dimension of empowerment.

Appelbaum and Honeggar (1998) define competence as the accomplishment you feel in skilfully performing task activities you have chosen. The feeling of competence involves the sense that you are doing good quality work on a task. According to Thomas and Velthouse (1990) competence is the degree to which a person can perform task activities skilfully when he or she attempts to. Competence is analogous with self-efficacy, which refers to people's beliefs about their capability to exercise control over their own level of functioning and over events that affect their lives (Bandura, 1991). High selfefficacy feelings tend to result in initiating behaviours, high effort and persistence in the face of obstacles (Bandura, 1997). This is supported by Gist and Mitchell (1992) in their assertion that self-efficacy beliefs are considered to be the outcome of a process of weighing, integrating and evaluating information about one's capabilities. These in turn regulate the choices that people make and the amount of effort they apply to a given task. Judgements of self-efficacy also determine how much effort people will expend and how long they will persist in the face of obstacles or adverse experiences. 
According to Deci, Connell and Ryan (1989), self-determination is a sense of choice in initiating and regulating actions. It reflects autonomy over the initiation and continuation of work behaviour and processes, for example making decisions about work methods, pace and effort (Bell \& Staw, 1989; Spector, 1986). Appelbaum and Honeggar (1998) assert that choice is the opportunity you feel to select task activities that make sense to you and to perform them in ways that seem appropriate. The feeling of choice is the feeling of being free to choose, of being able to use your own judgement and act out your own understanding of the task. A sense that a person is controlled by events leads to tension, a more negative emotional tone and decreased self-esteem. Self-determination is consistent with notions of personal control (Keller \& Dansereau, 1995). Furthermore, for employees to feel empowered, they must perceive that their work environment is liberating rather than constraining, that their actions matter and that outcomes are affected by their decisions. Spector (1986) reports strong evidence of a positive relationship between feelings of perceived control and job performance, work satisfaction and stress.

Ashforth (1989) defines impact as the degree to which an individual can influence strategic, administrative and operating outcomes of work. According to Thomas and Velthouse (1990) impact is the degree to which behaviour is seen as making a difference in terms of accomplishing the purpose of a task. It is the accomplishment you feel in achieving a task purpose (Appelbaum \& Honeggar, 1998). It involves the sense that the task is moving forward, that your activities are really accomplishing something. Spreitzer and Quinn (1997) indicate that empowered people have a sense of impact. This means that people believe they can have an influence on their work unit and that others listen to their ideas. The impact dimension of empowerment extends the notion that individuals have some control over their own jobs to imply that they have some influence over larger organisational matters (Spreitzer, 1996). According to Ashforth (1989, 1990), if individuals believe that they can have an impact on the system in which they are embedded, and that they can influence organisational outcomes, they will be more likely to actually have an impact on their system through their work and thus will be seen as more effective. In contrast, individuals who do not believe that they can make a difference will be less likely to try as hard in their work, and hence will often be seen as less effective. According to Spreitzer and Quinn (1997) an employee will experience psychological empowerment and its associated consequences when all the components of psychological empowerment, namely meaning, competence, self-determination and impact, can be identified within the individual. These four dimensions, it is argued, combine additively to create an overall construct of psychological empowerment.

Job satisfaction is defined as the extent to which an employee feels positive or negative toward his job (Yousef, 2000). Employees compare their expected outcomes with the perceived real outcomes offered by the job. It is an affective or emotional reaction to a job, resulting from the comparison of actual outcomes with those that are desired, expected or felt to be deserved (Cranny, Smith \& Stone, 1992).

Job satisfaction has been conceptualised and operationalised as both a global construct and a multifaceted construct. One advantage of multidimensional measures of job satisfaction is that the components may relate differently to other variables of interest (Hirschfeld, 2000). The 20-item short form of the Minnesota Satisfaction Questionnaire (MSQ) (Weiss, Dawis, England \& Lofquist, 1967) is a popular faceted measure that is often used in job satisfaction research (Hirschfeld, 2000). The MSQ can be used to measure two distinct components, namely intrinsic job satisfaction and extrinsic job satisfaction. Intrinsic job satisfaction is the way a person feels about the nature of the job tasks themselves, while extrinsic job satisfaction is the way people feel about aspects of the work situation that are external to the job tasks (Hirschfeld, 2000).

Holdsworth and Cartwright (2003) claim that a decrease in job-related stress and an increase in job satisfaction are two of the key anticipated outcomes of the introduction of empowerment 
in the workplace. Low levels of empowerment in daily working life are strongly related to mental distress and excess chronic disease (Johnson, 1997) and many studies highlight the positive effect of empowerment on reduced incidence of sickness, absence and turnover (Ripley \& Ripley, 1993; Applebaum \& Honeggar, 1998).

Various studies (e.g. Koberg \& Colorado, 1999; Silver, 2000; Hancer, 2001) indicate that there is a statistically significant relationship between psychological empowerment and job satisfaction. These researchers state that individuals who perceive their jobs to be significant and worthwhile experience higher levels of job satisfaction than those who perceive their jobs as having little value. Spreitzer and Quinn (1997) examined each of the four dimensions of empowerment and their relationship to job. Meaning, self-determination and competence were all found to be associated with job satisfaction. The most powerful association was found with meaning, suggesting that to feel satisfied with work, employees need to feel energised by their work and put their hearts into their work. Conversely, Thomas and Tymon (1994), as well as Siegall and Gardner (2000) found no link between competence and job satisfaction. Other relevant research notes include meaning that is positively related to job satisfaction and job performance (Liden, Sparrowe \& Wayne, 2000). Fuller, Morrison, Jones, Bridger, and Brown (1999) found that psychological empowerment moderated the relationship between three of the four dimensions of transformational leadership and job satisfaction.

Based on the above literature and research review, the following hypotheses are formulated:

H1: Psychological empowerment as measured by the Measuring Empowerment Questionnaire (MEQ), is a four dimensional construct (meaningfulness, impact, competence, self-determination) with acceptable levels of internal consistency for each of its subscales.

H2: Job satisfaction as measured by the Minnesota Job Satisfaction Questionnaire (MSQ), is a two dimensional construct (extrinsic and intrinsic) with acceptable levels of internal consistency for each of its subscales.

H3: There is a relationship between psychological empowerment and that of job satisfaction.

H4: Psychological empowerment holds predictive value with regard to job satisfaction.

\section{2 \\ Research method}

\subsection{Research design}

A cross-sectional design with a survey as a technique of data collection was used to determine the objectives of this research. Crosssectional designs are used to examine groups of subjects at various stages of development simultaneously, while the survey describes a technique of data collection in which questionnaires are used to gather data about an identified population (Burns \& Grove, 1993). This design is well-suited to the descriptive and predictive functions associated with correlational research, whereby relationships between variables are examined (Shaughnessy \& Zechmeister, 1997).

\subsection{Study population}

The study population $(N=91)$ for studying the relationship between psychological empowerment and job satisfaction included representatives from a business unit of a petrochemical industry in Mpumalanga, South Africa. The representatives were a relatively young team, with 41 per cent in the age group of 25-35 years and 15 per cent in the age group of 36-45 years. Concerning length of service with the company, 41.6 per cent worked between 1 and 4 years in the organisation, and 32 per cent for longer than 10 years. Sixty-one percent have $\mathrm{B}$ degrees and 13 per cent have honours degrees.

\subsection{Measuring instruments}

Two questionnaires were used in the empirical study, namely the Measuring Empowerment 
Questionnaire (Spreitzer, 1995) and the Minnesota Job Satisfaction Questionnaire (Weiss, Dawis, England \& Lofquist, 1967).

The Measuring Empowerment Questionnaire (MEQ) (Spreitzer, 1995) was used to measure the participants' psychological empowerment. This questionnaire consists of 12 items, with 3 items for each of the 4 subdimensions. The subdimensions are meaning, competence, selfdetermination and impact. Sample items include "The work I do is meaningful" (meaning); "I am confident about my ability to do my job" (competence); "I have significant autonomy in determining how I do my job" (self-determination); and "My impact on what happens in my department is large" (impact). Buckle (2003) reported a Cronbach alpha coefficient of 0.88 for total psychological empowerment and Malan (2002) reported alpha coefficients for all the four subdimensions of psychological empowerment to vary from 0.68 to 0.83 .

The Minnesota Job Satisfaction Questionnaire (MSQ) (Weiss et al., 1967) indicates how satisfied or dissatisfied respondents are with their jobs by asking respondents to rate themselves by using a five-point scale $(1=$ very dissatisfied to $5=$ very satisfied). Both the revised MSQ short form (13 items) and original MSQ short form (20 items) measures intrinsic job satisfaction and extrinsic job satisfaction, using questions like: "The chance to be 'somebody' in the community"; "The way my supervisor handles his/her workers", and "The praise I get for doing a good job". The original model (Weiss et al., 1967), consisting of 20 items, as well as the revised MSQ short form consisting of 13 items was tested in this study. Hirschfeld (2000) found that a two-factor model (intrinsic and extrinsic job satisfaction) is superior to a one-factor model (total job satisfaction). Alpha coefficients for both the scales of the revised and original MSQ short form were higher than 0.80 (Hirschfeld, 2000).

\subsection{Statistical analysis}

Structural equation modelling (SEM) methods as implemented by AMOS (Arbuckle, 1997) were used to test the factorial model for the
MSQ and MEQ, using the maximum likelihood method. The $\chi^{2}$ statistic and several other goodness-of-fit indices summarise the degree of correspondence between the implied and observed covariance matrices. Jöreskog and Sörborn (1993) suggest that the $\chi^{2}$ value may be considered more appropriately as a badnessof-fit rather than as a goodness-of-fit measure in the sense that a small $\chi^{2}$ value is indicative of good fit. Researchers have addressed the $\chi^{2}$ limitations by developing goodness-of-fit indices that take a more pragmatic approach to the evaluation process. One of the first fit statistics to address this problem was the $\chi^{2} /$ degrees of freedom ratio (CMIN/DF) (Wheaton, Muthén, Alwin \& Summers, 1977). These criteria commonly referred to as "subjective" or "practical" indices of fit are typically used as adjuncts to the $\chi^{2}$ statistic.

The Goodness-of-Fit Index (GFI) indicates the relative amount of the variances/covariances in the sample predicted by the estimates of the population. It usually varies between 0 and 1 and a result of 0.90 or above indicates a good model fit. In addition, the Adjusted Goodness-of-Fit Index (AGFI) is given. The AGFI is a measure of the relative amount of variance accounted for by the model, corrected for the degrees of freedom in the model relative to the number of variables. The GFI and AGFI can be classified as absolute indices of fit because they basically compare the hypothesised model with no model at all (Hu \& Bentler, 1995). The parsimony goodness-of-fit index (PGFI) addresses the issue of parsimony in SEM (Mulaik et al., 1989). The PGFI takes into account the complexity (i.e. number of estimated parameters) of the hypothesised model in the assessment of overall model fit and provides a more realistic evaluation of the hypothesised model. Mulaik et al. (1989) suggest that indices in the 0.90s accompanied by PGFIs in the 0.50 s are not unexpected. However, values higher than 0.80 are considered to be more appropriate (Byrne, 2001).

The Normed Fit Index (NFI) is used to assess global model fit. The NFI represents the point at which the model being evaluated falls on a scale running from a null model to perfect fit. 
This index is normed to fall on a 0 to 1 continuum. Marsh, Balla and Hau (1996) suggest that this index is relatively insensitive to sample sizes. The Comparative Fit Index (CFI) represents the class of incremental fit indices in that it is derived from the comparison of a restricted model (i.e. one in which structure is imposed on the data) with that of an independence (or null) model (i.e. one in which all correlations among variables are zero) in the determination of goodness-of-fit. The Tucker-Lewis Index (TLI) (Tucker \& Lewis, 1973 ) is a relative measure of covariation explained by the model, which is specifically developed to assess factor models. For these fit indices (NFI, CFI and TLI), it is more or less generally accepted that a value of less than 0.90 indicates that the fit of the model can be improved (Hoyle, 1995), although a revised cut-off value close to 0.95 has recently been advised (Hu \& Bentler, 1999).

Browne and Cudeck (1993) suggest using the Root Mean Square Error of Approximation (RMSEA) and the 90 per cent confidence interval of the RMSEA. The RMSEA estimates the overall amount of error; it is a function of the fitting function value relative to the degrees of freedom. The RMSEA point estimate should be 0.05 or less and the upper limit of the confidence interval should not exceed 0.08 . Hu and Bentler (1999) suggest a value of 0.06 to be indicative of good fit between the hypothesised model and the observed data. MacCallum, Browne and Sugawara (1996) recently elaborated on these cut-off points and noted that RMSEA values ranging from 0.08 to 0.10 indicate mediocre fit, and those greater than 0.10 indicate poor fit.

The data analysis was carried out with the help of the SAS programme (SAS Institute, 2000). Cronbach alpha coefficients $(\alpha)$ and inter-item correlation coefficients were used to assess the internal consistency of the measuring instruments (Clark \& Watson, 1995). Descriptive statistics (e.g. means, standard deviations, skewness and kurtosis) were used to analyse the data. Pearson product-momentum correlation coefficients were used to specify the relationships between the variables. In cases where the distribution of scores was skew,
Spearman correlation coefficients were computed. The level of statistical significance was set at $p \leq 0.05$. Steyn (2002) criticises the sole uses of statistical significance testing and recommends that effect sizes be established to determine the importance of a statistically significant relationship. While the reporting of effect sizes are encouraged by the American Psychological Association (APA) in their Publication Manual (APA, 1994), most of these measures are seldom found in published reports (Steyn, 2002). Therefore, effect sizes were computed to assess the practical significance of relationships in this study. A cut-off point of 0.30 , which represents a medium effect (Cohen, 1988; Steyn, 2002), was set for the practical significance of correlation coefficients.

A multiple regression was done to determine the percentage variance in job satisfaction by predicted psychological empowerment. According to Cohen (1988), a correlation can best be understood by determining its square $\left(r^{2}\right)$.

\section{3}

Results

Structural equation modelling (SEM) methods were used to test factorial models for the MSQ and the MEQ. Data analyses proceeded as follows: firstly, a quick overview of model fit was done by looking at the overall $\chi^{2}$ value, together with its degrees of freedom and probability value. Global assessments of model fit were based on several goodness-of-fit statistics (GFI, AGFI, PGFI, NFI, TLI, CFI and RMSEA). Secondly, given findings of an ill-fitting initially hypothesised model, analyses proceeded in an exploratory mode. Possible misspecifications as suggested by the so-called modification indices were looked for, and eventually a revised, re-specified model was fitted to the data.

\subsection{Hypothesised model of job satisfaction}

The original MSQ Short-form items (see Hirschfeld, 2000, p. 258) were used. The original MSQ Short Form includes 12 items 
which measure intrinsic job satisfaction, and 8 items which measure extrinsic job satisfaction. The revised MSQ Short Form (Hirschfeld, 2000) consists of 6 items which measure intrinsic job satisfaction and 7 items which measure extrinsic job satisfaction. Table 1 presents fit statistics for the test of the various models.

Table 1

Goodness-of-fit statistics for the MSQ Short Form Models

\begin{tabular}{|l|c|c|c|c|c|c|c|c|c|c|}
\hline Model & $\chi^{2}$ & $\chi^{2} / \mathbf{d f}$ & RMR & GFI & AGFI & PGFI & NFI & TLI & CFI & RMSEA \\
\hline $\begin{array}{l}\text { Model } 1 \\
\text { (20 items) }\end{array}$ & 356.88 & 2.66 & 0.12 & 0.69 & 0.60 & 0.54 & 0.63 & 0.69 & 0.79 & 0.12 \\
\hline $\begin{array}{l}\text { Model 1 } \\
\text { (13 items) }\end{array}$ & 155.20 & 2.04 & 0.05 & 0.91 & 0.90 & 0.64 & 0.90 & 0.89 & 0.90 & 0.08 \\
\hline
\end{tabular}

Table 1 shows that the revised model of MSQ Short Form resulted in a better fit compared with the original model. Although the $\chi^{2}$ value of the revised model is still statistically significant, it is substantially lower than the value of the original model. Also, the RMR value lower than 0.05 and the GFI, AGFI, NFI, TLI and CFI values higher than 0.90 and RMSEA value lower than 0.08 , are indicative of an acceptable fit.

\section{Table 2}

Hypothesised model of psychological empowerment

\begin{tabular}{|l|c|c|c|c|c|c|c|c|c|c|}
\hline Model & $\chi^{2}$ & $\chi^{2} / \mathbf{d f}$ & RMR & GFI & AGFI & PGFI & NFI & TLI & CFI & RMSEA \\
\hline $\begin{array}{l}\text { Original } \\
\text { model }\end{array}$ & 195.36 & 1.98 & 0.04 & 0.89 & 0.77 & 0.53 & 0.99 & 0.93 & 0.95 & 0.07 \\
\hline
\end{tabular}

The full 4-factor model consisting of all 12 items of the MEQ was tested. Table 2 presents fit statistics for the test of the original model. As seen in Table 2, the original model of the MEQ is accepted for the reasons that the RMR value lower than 0.05 and the NFI, TLI and CFI values higher than 0.90 and RMSEA value lower than 0.08 are indicative of an acceptable fit.

Descriptive statistics, Cronbach alpha coefficients and the inter-item correlation coefficients of the MSQ and the MEQ for engineers $(N=91)$ in a chemical industry are reported in Table 3.

Table 3

Descriptive statistics for the measuring instruments

\begin{tabular}{|l|c|c|c|c|c|c|c|}
\hline Instruments & $\mathbf{N}$ & $\mathbf{X}$ & $\mathbf{S D}$ & Skewness & Kurtosis & $\alpha$ & $\begin{array}{c}\text { Inter-item } \\
\text { correlation }\end{array}$ \\
\hline $\begin{array}{l}\text { Psychological } \\
\text { empowerment }\end{array}$ & $\mathbf{9 1}$ & $\mathbf{5 8 . 3 4 4}$ & $\mathbf{4 . 2 5 3}$ & $\mathbf{- 0 . 2 3}$ & $\mathbf{- 0 . 7 0}$ & $\mathbf{0 . 9 4}$ & $\mathbf{0 . 5 7 5}$ \\
\hline Meaning & 91 & 14.988 & 4.650 & -0.49 & -0.54 & 0.95 & 0.580 \\
\hline Competence & 91 & 16.811 & 3.057 & -0.52 & -0.36 & 0.85 & 0.670 \\
\hline Self-determination & 91 & 14.288 & 4.267 & -0.38 & -0.37 & 0.87 & 0.640 \\
\hline Impact & 91 & $\mathbf{1 2 . 2 5 5}$ & 5.006 & -0.27 & -0.93 & 0.95 & 0.867 \\
\hline Job satisfaction & $\mathbf{9 1}$ & $\mathbf{4 9 . 1 6 6}$ & $\mathbf{1 0 . 0 3 0}$ & $\mathbf{- 0 . 3 7}$ & $\mathbf{- 0 . 2 7}$ & $\mathbf{0 . 9 1}$ & $\mathbf{0 . 4 0 6}$ \\
\hline Intrinsic job satisfaction & 91 & 32.177 & 7.028 & -0.469 & -0.397 & 0.88 & 0.480 \\
\hline Extrinsic job satisfaction & 91 & 16.988 & 4.147 & -0.451 & -0.103 & 0.81 & 0.481 \\
\hline
\end{tabular}


Table 3 indicates that acceptable Cronbach alpha coefficients were obtained on all the dimensions of the MSQ and the MEQ, varying from 0.81 to 0.95 (see Nunnally \& Bernstein, 1994). The finding is consistent with reports of a Cronbach alpha coefficient of 0.88 in a study within the chemical industry (Buckle, 2003). The Cronbach alpha coefficients of the four subdimensions of psychological empowerment ranged from 0,85 to 0.95 in this study. Consistent with these findings, Malan (2002) reported alpha coefficients of 0.68 to 0.83 for the four subdimensions of the MEQ in a coal mine. Most of the inter-item correlations were acceptable, although values higher than the cut-off point of 0.50 (Clark \& Watson, 1995) were obtained for the psychological empowerment questionnaire. Further research is needed to establish the cause of this. All scores appear to be normally distributed (skewness and kurtosis smaller than 1).

Factor analysis was done on the MSQ and the MEQ to establish construct validity. The ideal with construct validity is to have one factor extracted per sub-dimension measured, a high variance and high commonalities. With regard to the MSQ, eigenvalues (above 1) and scree plot indicated that two factors, which explained 56.91 per cent of the variance of this questionnaire, were extracted. Hypothesis 2, stating that job satisfaction as measured by the Minnesota Job Satisfaction Questionnaire, displays internal consistency is accepted.

Regarding the $\mathrm{MEQ}$, eigenvalues and scree plot indicated that only three factors, which explained 83.49 per cent of the variance, could be extracted, whereas four factors were expected. This finding is in line with Spreitzer's (1995) recommendations for continued work on the discriminant validity of the MEQ. Hypothesis 1 namely, that psychological empowerment as measured by the Measuring Empowerment Questionnaire indicated acceptable levels of internal consistency can be accepted.

Given the limited sample size employed in this research, these findings could however have been obtained by pure chance, hence all subsequent analyses were done, making use of the originally intended four-dimensional scale.

Table 4 shows the relationship between psychological empowerment, its subdimensions and job satisfaction. Although all the correlations between the variables were statistically significant $(p<0.05)$, some were of medium and large practical significance. Table 4 shows practical and significant correlation coefficients of large effect $(0.73)$ between job satisfaction (total score) and psychological empowerment (total score), suggesting that higher levels of job satisfaction are associated with higher levels of psychological empowerment. This finding corresponds with the findings of research in South African context by Buckle (2003) and Dwyer (2001), who also found correlations of large effect between psychological empowerment and job satisfaction.

Table 4

The relationship between psychological and job satisfaction

\begin{tabular}{|c|c|c|c|c|c|c|c|c|}
\hline Item & 1 & 2 & 3 & 4 & 5 & 6 & 7 & 8 \\
\hline 1. Job satisfaction (Total) & - & & & & & & & \\
\hline 2. Intrinsic job satisfaction & $0.95^{* * \dagger}$ & - & & & & & & \\
\hline 3. Extrinsic job satisfaction & $0.92^{* *}+$ & $0.78^{* *+}$ & - & & & & & \\
\hline $\begin{array}{l}\text { 4. Psychological } \\
\text { empowerment (Total) }\end{array}$ & $0.73^{* *}+$ & $0.78^{* *+}$ & $0.59^{* *}+$ & - & & & & \\
\hline 5. Meaning & $0.63^{* *}+$ & $0.68^{* * \dagger}$ & $0.50 * *+$ & $0.84 * *+$ & - & & & \\
\hline 6. Competence & $0.34^{*}+$ & $0.33^{*}+$ & $0.27+$ & $0.68^{* *+}$ & $0.49^{*}+$ & - & & \\
\hline 7. Impact & $0.65^{* *}+$ & $0.71^{* *}+$ & $0.53^{* *+}$ & $0.87^{* *}+$ & $0.56^{* *+}$ & $0.45^{*}+$ & - & \\
\hline 8. Self-determination & $0.75^{* *+}$ & $0.78^{* *+}$ & $0.61^{* *+}$ & $0.92 * *+$ & $0.69^{* *+}$ & $0.50^{* *+}$ & $0.81^{* *}+$ & - \\
\hline
\end{tabular}

*Correlation is practically significant: $r \geq 0.30$ (medium effect)

**Correlation is practically more significant: $r \geq 0.50$ (large effect)

+ Statistically significant $p \leq 0.05$ 
As indicated by Table 4, total psychological empowerment is positively related (large effect) to both job satisfaction subscales, as well as the total job satisfaction scale, suggesting that increased levels of psychological empowerment are associated with increased levels of intrinsic and extrinsic job satisfaction.

Table 4 indicates a correlation of large effect (0.63) between job satisfaction and the meaning subscale of the MEQ. Spreitzer et al. (1997), as well as Dwyer (2001) also found the meaning dimension to be positively related to job satisfaction. It can be concluded that when engineers in a petrochemical industry experience satisfaction in their jobs, they also tend to experience meaningfulness, which indicates that they have high values relative to their own ideals and standards.

A correlation of medium effect (0.34) was obtained with regard to total job satisfaction and competence, which corresponds with the findings of Malan (2002). Based on the findings reported in this study, it can be deduced that the respondents feel confident and have control over their own level of functioning and over events that affect their lives (Bandura, 1991) when they experience satisfaction with their jobs.

A relationship of large effect (0.65) was found between total job satisfaction and impact. It can be concluded that when engineers perceive themselves as impacting positively on the strategic, administrative and operating outcomes of their work, job satisfaction will tend to increase.

The relationship between job satisfaction and self-determination was found to be one of large effect $(0.75)$. This is the highest correlation obtained with regard to the psychological empowerment subscales and job satisfaction. Liden et al. (2000) however found that the meaning dimension of psychological empowerment explained the most variance (compared to the other three subscales) in predicting job satisfaction. This finding is higher than the ones reported by Liden et al. (2000) and Malan (2002), who reported correlations of 0.45 and 0.52 respectively. Consistent with their prior research, Spreitzer and Quinn (1997) also reported a positive relationship between job satisfaction and self-determination. Parker and Price (1994) explain that selfdetermination appears to enhance confidence, making tasks less stressful and more intrinsically rewarding. It can be concluded that the more employees perceive that they can use their own judgement and act on their own understanding of the task, the more the likelihood that they will be satisfied.

Regarding intrinsic job satisfaction, practically significant correlations of large effect were found with the meaning, impact and self-determination. A practically significant correlation of medium effect was obtained between intrinsic job satisfaction and competence. Increased levels of meaning, impact, self-determination, and competence thus appear to be associated with elevated levels of intrinsic job satisfaction. Similarly, practically significant correlations of large effect were obtained between extrinsic job satisfaction and the meaning, impact and selfdetermination scales, suggesting that as meaning, impact and self-determination increases, extrinsic job satisfaction is likely to increase commensurately. Although the correlation between extrinsic job satisfaction and competence was found to be statistically significant, this correlation was not particularly strong, falling below the 0.30 level.

In summary, all sub dimensions of psychological empowerment were found to be associated with increased job satisfaction, which corresponds with the findings of Spreitzer et al. (1997, who also found the sub dimensions of psychological empowerment to be related to job satisfaction in two organisations.) Hypothesis 3, stating that there is a relationship between psychological empowerment and job satisfaction is accepted.

Finally, a multiple regression analysis was used to investigate to which extent the variance in job satisfaction can be explained by each of the empowerment dimensions. 
Table 5

Regression analysis regarding psychological empowerment and job satisfaction $\begin{array}{lll}R=0.8 & R^{2}=0.705 & \text { Adjusted } R^{2}=0.687\end{array}$ $p=0.000$

\begin{tabular}{|l|c|c|c|c|}
\hline \multicolumn{5}{|c|}{ Variables in the equation } \\
\hline $\begin{array}{l}\text { Independent } \\
\text { variables }\end{array}$ & B & $\begin{array}{c}\text { Standard error } \\
\text { of B }\end{array}$ & t-value & P \\
\hline Intercept & 1.712 & 0.231 & 7.41 & 0.0000 \\
\hline Meaning & 0.103 & 0.036 & 2.87 & 0.0051 \\
\hline Competence & -0.124 & 0.047 & -2.64 & 0.0097 \\
\hline Impact & -0.013 & 0.042 & -0.30 & 0.0764 \\
\hline Self-determination & 0.218 & 0.054 & 4.04 & 0.0001 \\
\hline
\end{tabular}

Table 5 indicates that 70.5 per cent of the variance of job satisfaction is explained by subdimensions of psychological empowerment. The multiple correlation of 0.84 is practically significant (large effect). Self-determination appears to be the strongest contributor to variance, whereas it is noted that impact does not contribute significantly $(\mathrm{p}>0.01)$ toward the variance in job satisfaction. This finding does not correlate with the research done by Holdsworth and Cartwright (2002), who found that meaning, self-determination and impact account for 31 per cent of the variation in job satisfaction. Hypothesis 4, indicating that psychological empowerment holds predictive value for job satisfaction, can partially be accepted.

\section{4}

\section{Discussion}

Acceptable Cronbach's alpha coefficients were obtained in this research, confirming the reliability of the MSQ and MEQ. The MSQ presented with acceptable average inter item correlation coefficients, although the average inter item correlation coefficients were slightly elevated on the MEQ (total and subscales), falling above the 0.50 cut-off point. Factor analyses confirmed the two-dimensional structure of the MSQ, although the MEQ presented with a three-factor, as opposed to a four-factor structure. Hypotheses 1 and 2 are therefore accepted.

Meaning concerns the fit between the requirements of the work role and a person's beliefs, values and behaviours. Spreitzer et al. (1997) refer to meaning as the "engine" of empowerment, as without it an employee will not feel empowered. A strong relationship was obtained between meaning and overall perceptions of empowerment (0.84), although even higher correlations were obtained between total psychological empowerment and impact (0.87) and self-determination (0.92), thus not lending support to the perception that meaning plays the largest role in psychological empowerment. Existing research (Spreitzer et al., 1997; Siegall \& Gardner, 2000; Liden et al., 2000) suggests a strong relationship between meaning and job satisfaction. These findings were confirmed in this study, indicating a practically significant correlation of large effect (0.63) between meaning and job satisfaction.

Competence was found to have a practically significant correlation of medium effect with total job satisfaction, as well as with intrinsic job satisfaction. Although extrinsic job satisfaction and competence were found to be statistically significantly related, this correlation was not found to be particularly strong, falling below the 0.30 level. This finding corresponds with the research of Malan (2002), who found a correlation of 0.29 between job satisfaction and competence. 
Impact demonstrated practically significant correlations of large effect with total job satisfaction, as well as the intrinsic and extrinsic subscales. Within the organisation where the research was conducted, the engineers participated in managerial processes and therefore perceptions of impact are related to influence over organisational processes (extrinsic job satisfaction) and achievement (intrinsic job satisfaction).

Self-determination was found to be strongly linked to all areas of job satisfaction, which corresponds with the findings of Liden et al. (2000) and Malan (2002), although the correlation in this study was found to be substantially higher. A practically significant correlation of large effect was found between total psychological empowerment and total job satisfaction. This finding is supported by Laschinger and Havens (1998), who reported a correlation of large effect between nurses' perceptions of psychological empowerment and overall job satisfaction in the United States. Buckle (2003) also reported a correlation of large effect between psychological empowerment and job satisfaction in a chemical organisation in South Africa. Based on the results obtained in this study, it can be deduced that engineers who perceive themselves as being psychologically empowered, will experience higher levels of job satisfaction. Hypothesis 3 can therefore be accepted.

Multiple regression analysis indicated that the dimensions of psychological empowerment predicted 70.5 per cent of the variance of job satisfaction, although impact was not found to contribute significantly in this regard. The results obtained in this study tend to partially support the present study's hypotheses that psychological empowerment holds predictive value with regard to job satisfaction.

This study had several limitations. Firstly, the sample size is a limitation, as well as the fact that this research was conducted in a business unit of a petrochemical industry, implying that the results cannot be generalised to other settings. Job satisfaction was measured in general, instead of focusing on specific aspects of the job, such as reward, work environment, etc. Future studies could yield invaluable results if the scope of research can be extended. The long version of the job satisfaction questionnaire could gather important information that points to specific aspects that employees are satisfied or dissatisfied with.

A further limitation of this study was its reliance on self-report measures. The exclusive use of self-report measures in validation studies increases the likelihood that at least part of the shared variance between measures can be attributed to method variance. Regarding research design, future studies should focus on longitudinal designs where causal inferences can be made.

\section{5}

\section{Recommendations}

The point of departure for the organisation is to acknowledge that psychological empowerment is not a set of management practices, but rather an individual mind-set, a proactive orientation regarding the employee's role in the organisation. This does not mean that the role of structural factors such as leadership, culture or climate are discarded, but rather to emphasise that organisations require employees who feel personally connected to the organisation and ready to act on its behalf.

An educational experience or innovative programme should be undertaken to build on and increase the level of psychological empowerment experienced by engineers. This programme should entail an in-depth personal evaluation and cognitive framing in order to allow individuals to visualise themselves and their environment through a different lens. This in-depth, personal evaluation should focus on personal mastery, reshaping mind-sets, personal development and self-management, geared to the outcome of personal transformation and a change in the individual's cause map or schema. This will help engineers to start thinking about how they can refocus themselves in relation to their work and see themselves as partners in the business rather than "cogs in the wheel".

Through this process, the engineers will develop a sense of meaning and ownership regarding the company and begin to understand 
how their work roles and behaviour affect its success. Through this new definition of the self and roles, engineers should be able to engage in new patterns of actions. This will contribute to synergy between the goals, ideals and beliefs of individuals and what the organisation wants to achieve.

The organisation should ensure that there is capacity for continuous learning, in terms of providing the skills and abilities which individuals need to feel competent. Through this process, the organisation emerges as a learning organisation, continuously striving to identify and learn new skills for improving processes. The development of skills on technical, administrative and interpersonal matters is important, for example production, problemsolving and interpersonal skills. It is recommended that mentoring and coaching programmes, on-the-job-training, special assignments and job rotation are included in the process. This is pivotal to ensure that engineers are confident about their abilities to execute tasks given to them. The relevance of this recommendation is highlighted by the fact that the majority of engineers ( 41.6 per cent) have 14 years service with the company and that they are at the beginning phase of employment. If this action is encouraged, these new patterns will stimulate future action, recognising the importance of a continuous learning mind-set. Their cognitions will become more complex, allowing for greater learning and growth, which in turn will lead to increased self-confidence.

The organisation is further advised to make a conscious effort to demonstrate trust and confidence in engineers. This can be done by offering support and encouragement. The ultimate goal is to allow engineers to have a sense that they are free to choose how to do their work, rather than being micro-managed. If support is weak or lacking, employees will worry about seeking permission before acting rather than asking for pardon in case they make mistakes. They must believe that the company will support them as they learn and grow. The aim with self-determination should be to encourage a significant degree of autonomy as the engineers perform their responsibilities. At this stage of the empowerment process, engineers should feel highly integrated with the organisation. Those that work with empowered engineers will start to feel energised themselves. Through this sharing, employees will be able to build networks to expand their power base in the organisation. This should lead to increased feelings of impact and draw individuals together to high levels of effort. Engineers will feel that people believe that they can have an influence on their work units and that others listen to their ideas.

The results of the study have indicated that 70.5 per cent of the variance in job satisfaction could be explained by psychological empowerment (meaning, competence and selfdetermination). It is suggested that the above recommendations be implemented in order to increase the level of job satisfaction experienced. Furthermore, the organisation is advised to conduct surveys to find out what would satisfy the engineers' needs. This survey should cover areas such as fringe benefits and employees' feelings about their work environments, culture and climate, which are factors not covered in this study. This should help to gather valuable information about how individual employees perceive the impact that external factors can have on their internal, psychological frame of reference. The organisation should also appreciate the amount of time employees have spent with the organisation. This can be done by giving recognition to employees for spending a certain amount of time with the organisation, by providing rewards such as long service certificates, bonuses and other non-monetary rewards. Younger employees should also be encouraged to attend seminars, lectures, conferences, and workshops in order to improve their development.

Longitudinal research should be undertaken to determine the long-term effects of psychological empowerment on job satisfaction. Follow-up measurements, perhaps six months or a year after the first measurement, will give an indication whether there are any changes in the levels of psychological empowerment and job satisfaction. Future studies should also focus on the implications of empowerment and job satisfaction on performance outcomes of engineers in a chemical industry. 


\section{References}

1 AMABILE, T.M.; CONTI, R.; COON, H.; LAZENBY, J.; \& HERRON, M. (1996)

"Assessing the work environment for creativity", Academy of Management Journal, 39(5): 11541184.

2 APA (2002) Publication manual of the American psychological association (5 $5^{\text {th }}$ ed.), Washington, DC.

3 APPELBAUM, S.H. \& HONEGGAR, K. (1998) "Empowerment: A contrasting overview of organisations in general and nursing in particular-An examination of organisational factors, managerial behaviours, job design, and structural power", Empowerment in organisations, 6(2): 29-50.

4 ARBUCKLE, J.L. (1997) Amos users' guide version 4.0, Smallwaters Corporation: Chicago, IL

5 ARVEY, R.D.; CARTER, G.W. \& BUERKLEY, D.K. (1991) "Job satisfaction: dispositional and situational influences”, In C.L. Cooper \& I.T. Robertson (eds.), International review of Industrial and organisational Psychology, Wiley: Chichester.

6 ASHFORTH, B.E. (1989) "The experience of powerlessness in organizations", Organisational Behaviour and Human Decision processes, 43: 207-242.

7 ASHFORTH, B.E. (1990) "The organisationally induced helplessness syndrome: A preliminary model", Canadian Journal of Administrative Sciences, 7: 30-36.

8 ASTLEY, W.G. \& SACHDEVA, P.S. (1984) "Structural sources of interorganisational power: A theoretical synthesis", Academy of Management Review, 9: 104-113.

9 BANDURA, A. (1991) "Social cognitive theory of self-regulation", Organisational Behaviour and Human Decision Processes, 50: 248-287.

10 BANDURA, A. (1997) Self-efficacy, the exercise of control, W.H. Freeman \& Company: New York.

11 BEACH, A.J. (1996) "Empowerment to the people: Creating an atmosphere for growth", Empowerment in Organisations, 4(1): 29-33.

12 BELL, N.E. \& STAW, B.M. (1989) "People as sculptor versus sculpture: The roles of personality and personal control in organizations", In M.B. Arther, D.T. Hall \& B.S. Lawrence (eds.), Handbook of career theory, Cambridge University Press: New York: 232-251.

13 BLOCK, P. (1987) The empowered manager: Positive political skill at work, San Jossey-Bass: Francisco.
14 BRIEF, A.P. \& NORD, W.R. (1990) Meanings of occupational work, Lexington Books: Lexington, MA.

15 BROWNE, M.W. \& CUDECK, R. (1993) "Alternative ways of assessing model fit", In K.A. BOLLEN \& J.S. LONG (eds.), Testing structural equation models, Sage: London: 136-162.

16 BUCKLE, P. (2003) Empowerment, organisational commitment and job satisfaction within a chemical organization, Unpublished masters' dissertation, PU for CHE, Potchefstroom.

17 BURNS, N. \& GROVE, S.K. (1993) The practice of nursing research, conduct, critique, and utilization, $\left(2^{\text {nd }}\right.$ ed.), W.B. Saunders. Philadelphia, Pa.

18 BUZAWA, E.S.; AUSTIN, T. \& BANNON, J. (1994) "The role of selected socio-demographic and job specific variables in predicting patrol officer job satisfaction: A re-examination ten years late", American Journal of Police, 13(2): 51-75.

19 BYRNE, B.M. (2001) Structural equation modeling with AMOS: Basic concepts, applications and programming, Erlbaum: Mahwah, NJ.

20 CLARK, L.A. \& WATSON, D. (1995)

"Construct validity: Basic issues in objective scale development", Psychological Assessment, 7: 309319

21 ClOETE, V.J.; CROUS, F. \& SCHEPERS, J.M. (2002) "The construction and evaluation of a scale of employee empowerment", South African Journal of Industrial Psychology, 28(2): 31-36.

22 COHEN, J. (1988) Statistical power analysis for the behavioural sciences (Rev. ed.), Academic Press: Orlando.

23 CONGER, J.A. \& KANUNGO, R.N. (1988) "The empowerment process: Integrating theory and practice", Academy of Management Review, 13(3): 471-476.

24 CORSUN, D.L. \& ENZ, C.A. (1999) "Predicting psychological empowerment among service workers: The effect of support-based relationships", Human Relations, 52(2): 205244.

25 CRANNY, C.J.; SMITH, P.C. \& STONE, E.F. (1992) Job satisfaction. How people feel about their jobs and how it affects their performance, Lexington Books: New York.

26 DANTZKER, M.L. (1994) "Identifying determinants of job satisfaction among police officers", Journal of Police Criminal Psychology, 10(1): 47-55. 
27 DECI, E.L.; CONNELL, J.P. \& RYAN, R.M. (1989). "Self-determination in a work organization", Journal of Applied Psychology, 74: 580-590.

28 DWYER, T.C. (2001) "Employee empowerment within a manufacturing organization", Unpublished masters' dissertation, $\mathrm{PU}$ for $\mathrm{CHE}$, Potchefstroom.

29 ECCLES, A. (1993) "The deceptive allure of empowerment”, Long Range Planning, 26(6): 1321.

30 FULLER, J.B.; MORRISON, R.; JONES, L.; BRIDGER, D. \& BROWN, V. (1999) "The effects of psychological empowerment on transformational leadership and job satisfaction", The Journal of Social Psychology, 139(3): 389-391.

31 GIST, M. \& MITCHELL, T.N. (1992) "Selfefficacy: A theoretical analysis of its determinants and malleability", Academy of Management Review, 17: 183-211.

32 GLYNN, M.A. (1996) "Innovative genius: A framework for relating individual and organisational intelligences to innovation", Academy of Management Journal, 21(4): 1081-1111.

33 GREGERSON, H.B. \& BLACK, J.S (1992) "Antecedents to commitment to a parent company and a foreign operation", Academy of Management Journal, 35(1): 65-90.

34 HACKMAN, J.R. \& OLDHAM, G.R. (1980) Work redesign, Reading, MA: Addison-Wesley.

35 HANCER, M. (2001) "An analysis of psychological empowerment and job satisfaction for restaurant employees", Dissertation Abstracts International Section A: Humanities \& Social Sciences, 62(4-A), pp. 1494.

36 HELLMAN, C.M. (1997) "Job satisfaction and intent to leave", Journal of Social Psychology, 137(6): 677-688.

37 HEYMANS, D.R. (2002) “The relationship between job insecurity, job satisfaction and organisational commitment of maintenance workers in a parastatal", Unpublished masters' dissertation, PU for CHE, Potchefstroom.

38 HIRSCHFELD, R.R. (2000) "Validity studies. Does revising the intrinsic and extrinsic subscales of the Minnesota Satisfaction Questionnaire Short Form make a difference?", Educational Psychological Measurements, 60: 255-270.

39 HOLDSWORTH, L. \& CARTWRIGHT, S. (2003) "Empowerment, stress and satisfaction: an exploratory study of a call centre", Leadership and Organizational Development Journal, 24(3): 131-140.
40 HOYLE, R.H. (1995) "The structural equation modeling approach: Basic concepts and fundamental issues", In R.H. HOYLE (Ed.), Structural equation modeling: Concepts, issues, and applications, Thousand Oaks, CA: Sage: 1-15.

41 HOYT, J. \& GERLOFF, E.A. (1999)

"Organisational environment, changing economic conditions, and the effective supervision of technical personnel. A management challenge", Journal of High Technology Management Research, 10(2): 275-289.

42 HU, L.-T. \& BENTLER, P.M. (1995)

"Evaluating model fit". In R.H. Hoyle (Ed.), Structural equation modeling: Concepts, issues, and applications, Thousand Oaks, CA: Sage: 7699.

43 JOHNSON, J.V. (1997) "Empowerment in future worklife", Scandinavian Journal of Work Environment and Health, 23(4): 23-70.

44 JÖRESKOG, K.G. \& SÖBORN, D. (1993) LISREL 8: Structural equation modeling with the SIMPLIS command language, Lawrence Erlbaum Associates: Hillsdale, NJ.

45 JUDGE, T.A.; LOCKE, E.A.; DURHAM, C.C. \& KLUGER, A.N. (1998) "Dispositional effects on job and life satisfaction: The role of core evaluations", Journal of Applied Psychology, 83(1): 17-34.

46 KANTER, R.M. (1977) Men and women of the corporation, Basic Books: New York.

47 KANTER, R.M. (1993) Men and women of the corporation, (2 ${ }^{\text {nd }}$ ed.), Basic Books: New York.

48 KELLER, T. \& DANSEREAU, F. (1995)

"Leadership and empowerment. A social exchange perspective", Human Relations, 48(2): 127-145.

49 KHWELA, S.M. (2001) “Organisational commitment and job satisfaction of nonacademic personnel at a tertiary education institution”, Unpublished masters' dissertation, PU for CHE, Potchefstroom.

50 KOBERG, C.S. \& COLORADO, B. (1999) "Antecedents and outcomes of empowerment: Empirical evidence from the health care industry" Group \& Organizational Management, 24(1): 71-91.

51 KRAIMER, M.; SEIBERT, S. \& LIDEN, R. (1999) "Psychological empowerment as a multidimensional construct: A test of construct validity”, Educational and Psychological Measurement, 59(1): 127-142.

52 LASHLEY, C. (1999) "Employee empowerment in service: a framework for analysis”, Personnel Review, 28(3): 169-191. 
53 LASCHINGER, H.K.S. \& HAVENS, D.S. (1998) "Staff nurse empowerment and perceived control over nursing practice", Journal of Nursing Administration, 26(9): 27-35.

54 LIDEN, R.C.; SPARROWE, R.T. \& WAYNE, S.J. (2000) "An examination of the mediating role of psychological empowerment on the relations between the job, interpersonal relationships and work outcomes", Journal of Applied Psychology, 85: 407-416.

55 LIDEN, R.C. \& TEWKSBURY, T.W. (1995) "Empowerment and work teams", In Reffis, G.R. Rosen, S.D. \& Barnum, D.T (Eds)., Handbook of Human Resource Management, Blackwell Publishers: Cambridge, MA: 386-403.

56 MACCALLUM, R.C.; BROWNE, M.W. \& SUGAWARA, H.M. (1996) "Power analysis and determination of sample size for covariance structure modelling", Psychological Methods, 1: 130-149.

57 MARSH, H.W.; BALLA, J.R. \& HAU, K.T. (1996) "An evaluation of Incremental Fit Indices: A clarification of mathematical and empirical properties", In G.A. MARCOULIDES \& R.E. SCHUMACKER (Eds.), Advanced structural equation modeling: Issues and techniques, Erlbaum: Mahwah, NJ: 315-353.

58 MALAN, M. (2002) "The relationship between psychological empowerment, job satisfaction and organisational commitment in a coal mine", Unpublished masters' dissertation, PU for CHE, Potchefstroom.

59 MAITLAND, R. (2002, August 18) "A brave new world at work", Sunday Times, p. 24.

60 MARSH, H.W.; BALLA, J.R. \& HAU, K.T. (1996) "An evaluation of incremental fit indices: A clarification of mathematical and empirical properties", In G.A. MARCOULIDES \& R.E. SCHUMACKER (Eds.), Advanced structural equation modelling: Issues and techniques, Erlbaum: Mahwah, NJ: 315-353.

61 MENON, S.T. (2001) "Employee empowerment: An integrative psychology approach", Applied Psychology: An International Review, 50(1): 153-180.

62 MISHRA, A.K. \& SPREITZER, C.A. (1998) "Explaining how supervisors respond to downsizing: the roles of trust, empowerment, justice and work redesign", Academy of Management Review, 23(3): 567-588.

63 MULAIK, S.A.; JAMES, L.R.; VAN ALTINE, J.; BENNETT, N.; LIND, S. \& STILLWELL, C.D. (1989) "Evaluation of goodness-of-fit indices for structural equation models", Psychological Bulletin, 105: 430-445.
64 NAUDÈ, J.L.P. (1999) "Psychological strengths and job satisfaction of representatives in the fertiliser industry", Unpublished masters' dissertation, PU for CHE, Potchefstroom.

65 NUNNALLY, J.C. \& BERNSTEIN, I.H. (1994) Psychometric theory ( $3^{\text {rd }}$ ed.), McGraw-Hill: New York.

66 PARKER, L.E. \& PRICE, R.H. (1994)

"Empowered managers and empowered workforce: The effects of managerial support and managerial perceived control on workers' sense of control over decision making", Human Relation, 49(8): 911-927.

67 PETERS, T. (1997) The circle of Innovation, London, UK: Hodder \& Stoughton.

68 RIPLEY, R.E. \& RIPLEY, M.J. (1993) "Empowering management in innovative organizations in the 1990s: part 1", Empowerment in Organizations, 1(1): 29-40.

69 ROTHMAN, S. (2000) "Sense of coherence, locus of control on job satisfaction", Paper presented at the $27^{\text {th }}$ International congress of Psychology, July, Stockholm, Sweden.

70 SAGIE, A. (1998) "Employee absenteeism, organisational commitment, and job satisfaction: Another look", Journal of Vocational Behaviour, 52: $156-171$.

71 SALEH, S.D. \& DESAI, K. (1990) "An empirical analysis of job stress and job satisfaction of engineers", Journal of Engineering and Technology Management Research, 7: 37-48.

72 SAS INSTITUTE. (2000) The SAS System for Windows: Release 8.01, SAS Institute Inc.: Cary, NC.

73 SHAUGHNESSY, J.J. \& ZECHMEISTER, E.B. (1997) Research methods in psychology, $\left(4^{\text {th }}\right.$ ed.), McGraw-Hill: New York.

74 SCHACKLETON, V. (1995) Business leadership, Routledge: London.

75 SIEGALL, M. \& GARDNER, S. (2000) "Contextual factors of psychological empowerment”, Personnel Review, 29(5/6): 1-18.

76 SILVER, S.R. (2000) "Perceptions of empowerment in engineer workgroups: The linkage to transformational leadership and performance", Dissertation Abstracts International Section A: Humanities \& Social Sciences, 61(5-A): 1721.

77 SPECTOR, P.E. (1986) "Perceived control by employees: A meta-analysis of studies concerning autonomy and participation at work", Human Relations, 39: 1005-1016.

78 SPREITZER, G.M. (1995) "Psychological empowerment in the workplace: Dimensions, 
measurement and validation", Academy of Management Journal, 38: 1142-1465.

79 SPREITZER, G.M. (1996) "Social structural characteristics of psychological empowerment", Academy of Management Journal, 39: 483-504.

80 SPREITZER, G.M.; KIZILOS, M.A. \& NASON, S.W. (1997) "A dimensional analysis of the relationship between psychological empowerment and effectiveness, satisfaction and strain”, Journal of Management, 23: 679-704.

81 SPREITZER, G.M. \& QUINN, R.E. (1997) "The road to empowerment: Seven questions every leader should consider", Organisational Dynamics, 26(2): 37-48.

82 STEYN, H.S. (1999) "Praktiese betekenisvolheid: Die gebruik van effekgroottes" Wetenskaplike bydraes - Reeks B: Natuurwetenskappe, Nr. 117, Potchefstroom: PU vir CHO.

83 STEYN, H.S. (2002) "Practically significant relationships between two variables", South African Journal of Industrial Psychology, 28(3): 10-15.

84 THOMAS, K.W. \& TYMON, W.G. Jr. (1994) "Does empowerment always work; understanding the role of intrinsic motivation and personal interpretation”, Journal of Management Systems, 6(2): 1-13.
85 THOMAS, K.W. \& VELTHOUSE, B.A. (1990) "Cognitive elements of empowerment: An interpretive model intrinsic task motivation", Academy of Management Review, 15: 666-681.

86 TUCKER, L.R. \& LEWIS, C. (1973) “A reliability coefficient for maximum likelihood factor analysis", Psychometrika, 38: 1-10

87 WEISS, D.J.; DAWIS, R.V.; ENGLAND, G.W. \& LOFQUIST, L.H. (1967) Manual for the Minnesota Job Satisfaction Questionnaire,: University of Minnesota: Minneapolis, MN.

88 WELMAN, J.C. \& BASSON, P.A. (1995) "The interrelationship between the work experience of distance education students, job satisfaction, and academic achievement", Journal of Industrial psychology, 21(1): 14-17.

89 WHEATON, B.; MUTHÉN, B.; ALWIN, D.F. \& SUMMERS, G.F. (1977) "Assessing reliability and stability in panel models", In D.R. Heise (Ed.), Sociological methodology, San Francisco: Jossey-Bass: 84-136

90 YOUSEF, D.A. (2000) “Organizational commitment and job satisfaction as predictors of attitudes towards organizational change in a nonwestern setting", Journal of Organizational Change Management, 29(5): 1-17. 